\title{
Precision Attachment and Magnet Retained Maxillary Prosthesis Continuous with Orbital Prosthesis
}

\author{
Shilpa Shirlal ${ }^{1}$, Sarthak Bhola ${ }^{2}$, Uzma Belgaumi ${ }^{3}$, Avinash Mehendale ${ }^{4}$, Hema Kanathilla ${ }^{5}$ \\ ${ }^{1}$ Department of Prosthodontics, Care and Cure Dental Clinic, Zirakpur, Punjab, India. ${ }^{2}$ Department of \\ Periodontics, Sri Sukhmani Dental College and Hospital, Derabassi, Punjab, India. ${ }^{3}$ Department of \\ Oral Pathology, School of Dental Sciences, KIMSDU, Karad, Maharashtra, India. ${ }^{4}$ Department of \\ Prosthodontics, A.J. Institute of Dental Sciences and Hospital, Mangalore, Karnataka, India. ${ }^{5}$ Department \\ of Prosthodontics, K.L.E.V.K. Institute of Dental Sciences, Belgaum, Karnataka, India.
}

\section{INTRODUCTION}

Rehabilitation of mid facial defect has a multiple clinical and technical difficulties. Lack of facial support, less retention and limited mouth opening are the major concerns that lead to technical and functional difficulties which in turn can cause psychological trauma in these patients. A correctly fabricated mid facial prosthesis helps to restore normal aesthetics, phonetics, masticatory function and deglutition for patients thus ensuring morale boosting of the patients. Implants are widely used for retaining maxillofacial prosthesis. However, for some patients, implants are not recommended due to their general poor health or old age, personal preference due to fear of invasive procedure, economic reasons because of expenditures on multiple surgeries, chemotherapy or radiotherapy. Hence, alternative treatment option to implants is use of precision attachment and magnets. The present case report explains the use of 0 ring attachment to improve the retention of maxillary prosthesis and magnet to connect the obturator and orbital prosthesis which helps to retain both the prosthesis.

Defects in the maxilla may be categorised into congenital defects due to genetic reasons and acquired defects resulting from surgery for oral neoplasms. ${ }^{1}$ Patients with these defects present with series of problems, which may include poor mastication, phonetics, aesthetics and social awkwardness leading to malnutrition and clinical depression and hence, should be handled with utmost care to improve the overall health of the patient. The chief objectives are to construct appliances which will restore function, aesthetics and speech, thereby benefiting the morale of patients. ${ }^{2}$

\section{PRESENTATION OF CASE}

A male patient aged 55 yrs. reported to the department with a large orbital defect on left side which was continuous with maxillary defect as a result of surgical excision of squamous cell carcinoma of the left maxillary sinus extending till the orbital contents. Intra oral examination revealed unilateral maxillectomy behind lateral incisor on the left side. The extent of the defect was large and there was direct communication between the orbital and oral cavity, hence, connection between obturator prosthesis and orbital prosthesis was planned to aid in retention of both the prosthesis. Intra oral diagnostic impressions were made with alginate (Tropicalgin, Zhermack) as this has good elastic recovery. The cast was surveyed for the desirable undercuts and a framework was planned.
Corresponding Author:

Dr. Shilpa Shirlal,

Department of Prosthodontics, Care and Cure Dental Clinic, Shop No3, Near MC Park, Opposite sarv Mangal Society, Lohgarh Road, Zirakpur, Punjab, India.

E-mail: drshilpashirlal32@gmail.com

DOI: $10.14260 / \mathrm{jemds} / 2020 / 836$

How to Cite This Article:

Shirlal S, Bhola S, Belgaumi U, et al. Precision attachment and magnet retained maxillary prosthesis continuous with orbital prosthesis. J Evolution Med Dent Sci 2020;9(50):3815-3818, DOI: $10.14260 / \mathrm{jemds} / 2020 / 836$

Submission 01-09-2020,

Peer Review 27-10-2020,

Acceptance 03-11-2020,

Published 14-12-2020.

Copyright (c) 2020 Shilpa Shirlal et al. This is an open access article distributed under Creative Commons Attribution License [Attribution 4.0 International (CC BY 4.0)] 
For additional retention, 0 ring precision attachment (OSO ring, Preat Corporation) was planned in the anterior segment. 11 and 12 were prepared to receive PFM (Porcelain-Fused-toMetal) crowns and 0 ring stud attachment (male patrix) was incorporated distal to 12. (Figure 1).

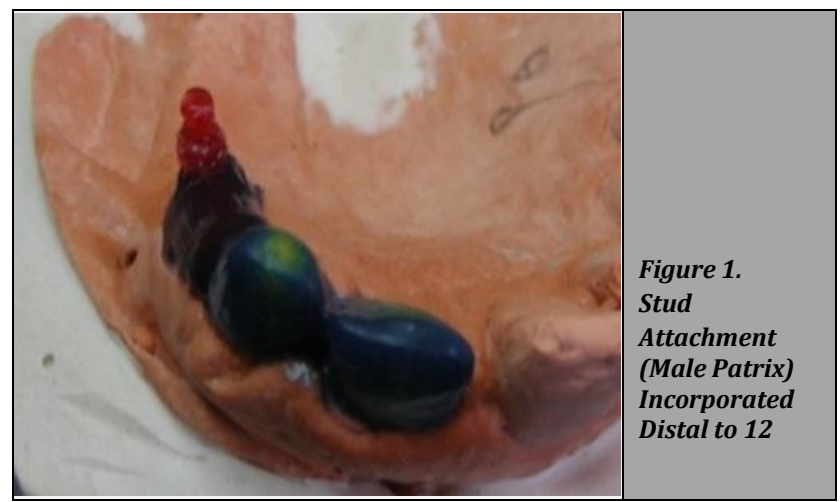

Once the crown was ready it was luted with the help of temporary cement so that it could be easily picked up in the final impression to make it the part of the master cast during the Removable Partial Denture (RPD) framework fabrication. Since, recording of large vertical component of the defect was necessary, split special tray with vertical extension with modelling wax in the defect area for recording the final impression (Figure 2) were made.

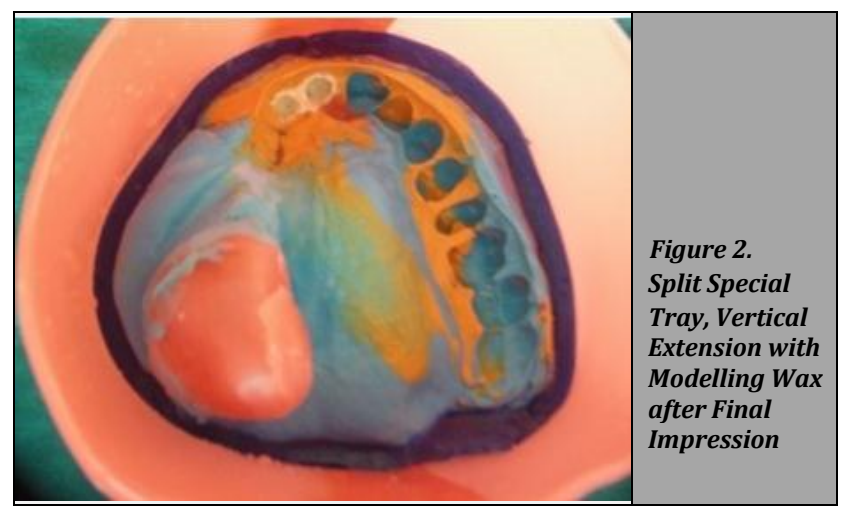

Impressions were made using elastomeric polyvinyl siloxane putty and light body material. After the master cast was obtained, it was surveyed, duplicated and a cast partial framework was fabricated and fitted on the master cast. A jaw relation recorded and was transferred to the articulator. Teeth selection was done keeping in mind the shade of adjacent and shape of occluding teeth. Trial denture (Figure 3).

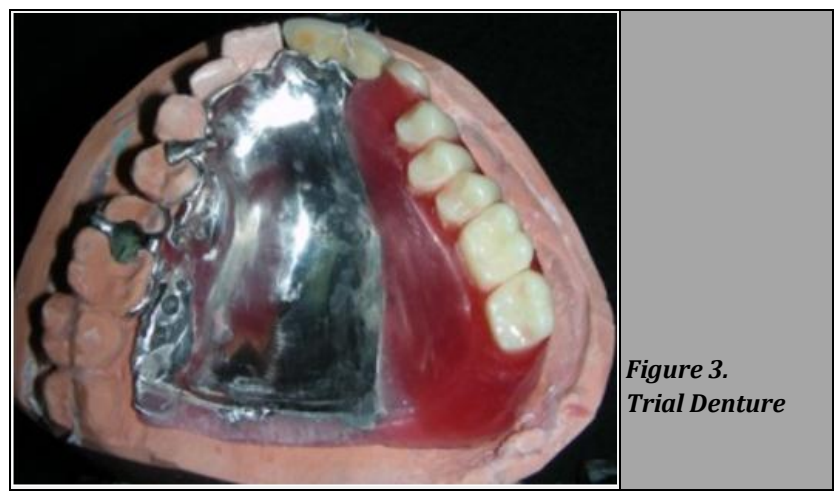

Fabricated and fitting was carried out. The denture was invested in a denture-curing flask and processed to fabricate a heat cure denture base resin closed hollow bulb obturator. (Figure 4).

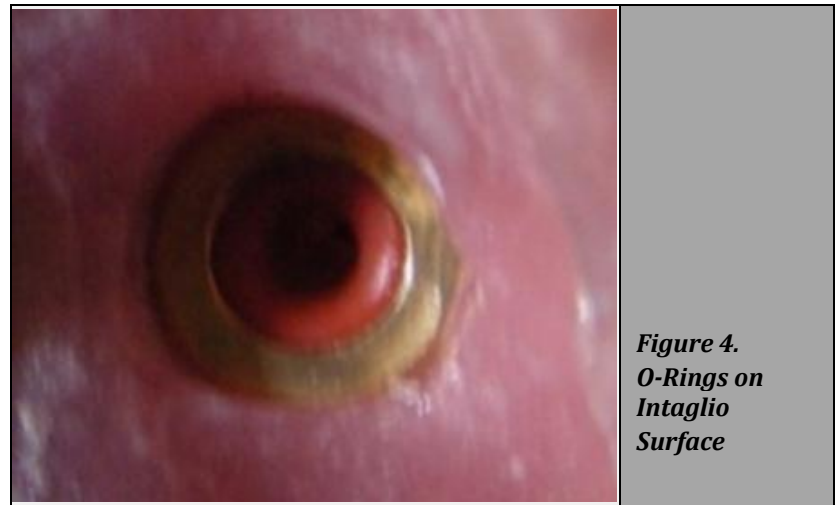

After processing, the obturator was polished, and the 0rings were incorporated into the upper partial denture in correspondence to the 0-ring posts and delivered to the patient (Figure 5).

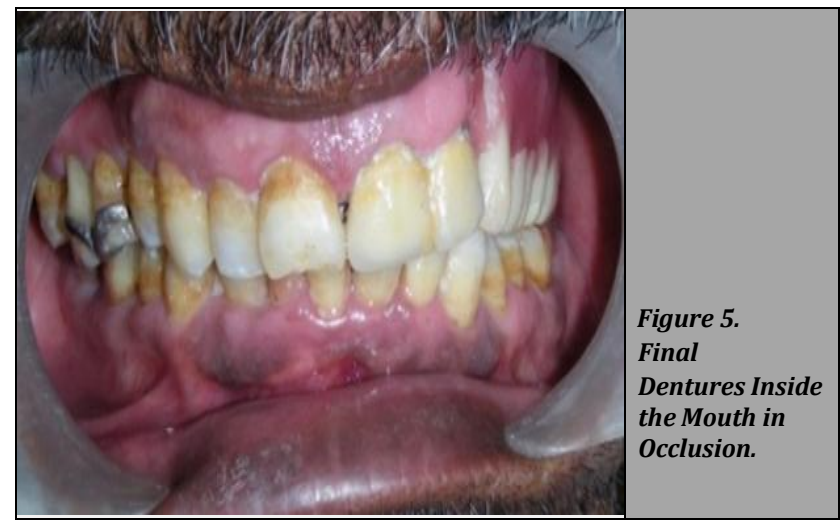

Meanwhile for ocular prosthesis, facial impressions were made with alginate impression material of thin consistency after beading the entire mid and upper segment of the face (Figure 6)

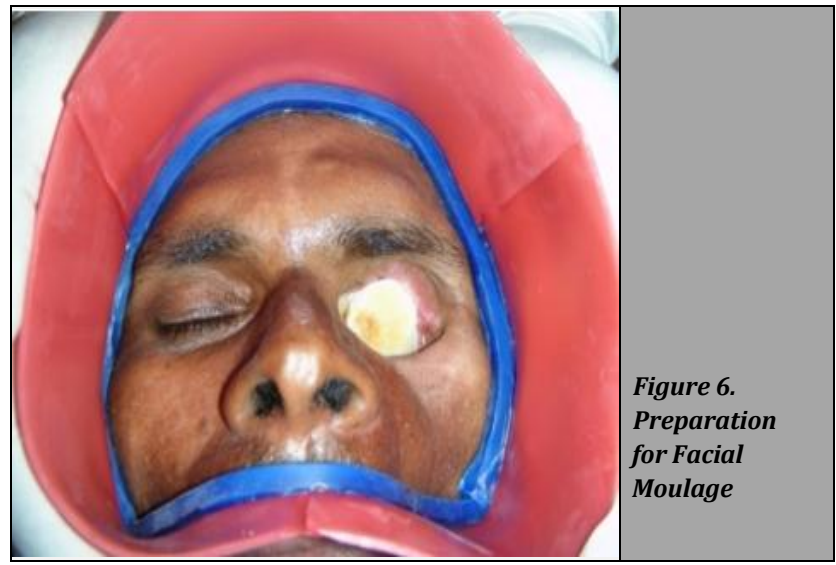

Breathing is ensured through mouth and nasal cavities were blocked with cotton. Care was taken to maintain even and minimal desired thickness of the impression material to avoid undue tissue compression. Wet gauze was placed over the impression to provide mechanical interlock between 
impression material and its base formed by type II gypsum products. Dental stone was mixed and poured in sections over the gauze to stabilize the impression and to aid in easy retrieval of impression after its final set. The facial moulage was prepared with type III gypsum product.

A suitable stock ocular prosthesis closely matching the colour, size, shape of the iris, and sclera of the other eye was selected as defect was relatively large. For locating the position of stock eye over the wax trial, measurements were made from the patient's facial midline to the centre of the pupil, and from the inner canthus of the eye to the nasal bridge. Both the measurements were made using transparent flexible plastic sheet when the patient was looking and fixing the contralateral eye at distant gaze. These measurements were transferred to the cast to aid in the position of the ocular portion of the orbital prosthesis which is matching the unaffected side.

The eye shell was then fixed in position on a bed of modelling wax based on measurements obtained. The anteroposterior position was adjusted and verified on the patient by observing from the profile and from the top of the head and matched with the contralateral side for proper positioning in all dimensions. Once the position was confirmed, the eyelids and the remaining portion of the orbit was sculpted in wax and tried in the patient's orbital defect and patient's consent was obtained. The wax sculpted prosthesis with the cast was flasked and dewaxed.

Room temperature vulcanizing medical graded silicone material (M511 Cosmesil) was mixed, a mix of white, brown, and light red pigment stains were blended into the base colour of silicon for intrinsic staining based on shade match with the patient's skin colour. Silicone was packed and cured at room temperature for $24 \mathrm{hrs}$. according to manufacturer's instructions. After ensuring the complete polymerization, the prosthesis was deflasked, retrieved, and finished. Then magnets were oriented and attached to nasal extension of the orbital prosthesis and nasal extension of obturator prosthesis (Figure 7).
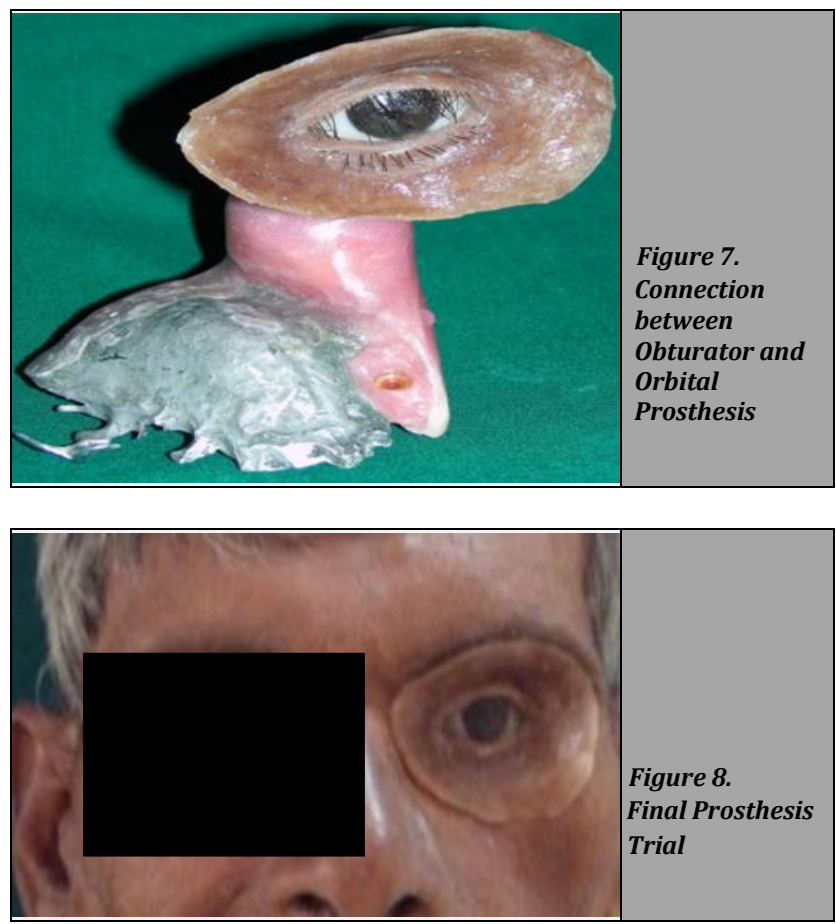

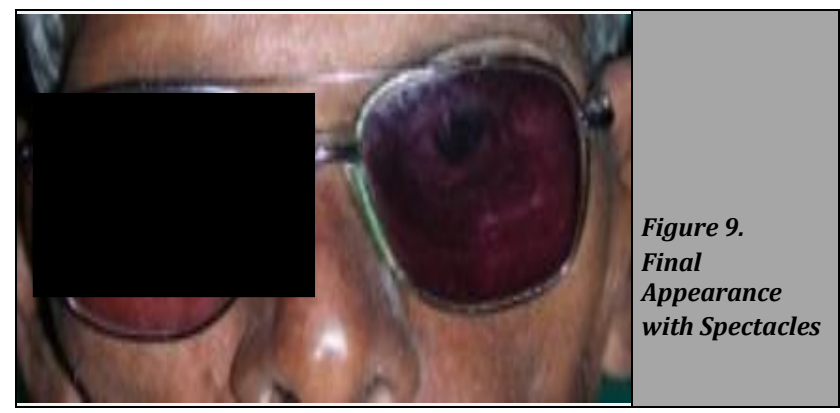

To secure both the prosthesis in place. Patient was advised to wear spectacles to hide the margins which were slightly thick (Figure 8). (Figure 9)

\section{DISCUSSION}

Prosthodontic rehabilitation of mid facial defect can be challenging and demanding with practical difficulties which requires utmost care. Lack of abutment teeth, hard and soft tissues may cause problems such as poor retention, absence of support and lack of prosthesis stability in treating patients with extensive mid facial defects. The present case report describes the use of 0 ring attachment for the retention of obturator and use of magnet to connect the obturator and orbital prosthesis which helps to retain both the prosthesis. Various techniques have been followed for improving retention of obturators. Schmidt et al. (2004) used zygomatic and standard endosseous implants and Dilek et al. (2007) reported the use of five mini-dental implants. However, implants may not feasible for all patients due to their poor general health or economic reasons. Hence, alternative treatment option like use of latex rubber balloon attached to a denture that was inflated with air to fill the surgical defect is explained by Payne and Welton (1965) and Yue-Zhong Hou et all (2012) has used an air valve in a hollow silicone obturator to manufacture an inflatable obturator that could be extended further into undercut area to retain itself exhibited adequate retention, stability and border sealing, thereby improving the masticatory, pronunciation and swallowing functions of patients is. ${ }^{3}$ Various methods of auxiliary retention for facial prostheses have been described in the literature; they include eye patches, ${ }^{4}$ prosthesis fastened to spectacle frame, 5 extensions from the denture, ${ }^{6}$ magnets, ${ }^{7}$ adhesives, ${ }^{8-10}$ Osseo integrated implants, ${ }^{11-12}$ and use of pin and socket of an electric plug for retention of obturator and orbital prosthesis. ${ }^{13}$

\section{CONCLUSIONS}

A maxillofacial prosthesis should restore the defect, be adequately retentive, comfortable to wear and be able to restore all functions like speech, deglutition, mastication, and be aesthetically pleasing. Success of these extensive prosthesis depends on the ease of placing and using theses prosthesis on regular basis for routine functions and their ability to simulate the unaffected side. Once the patient is comfortable and satisfied with the prosthesis, it will improve the general nutritional status and mental health of the patients and make 
them socially more active which in turn helps them lead a better life.

Financial or other competing interests: None.

Disclosure forms provided by the authors are available with the full text of this article at jemds.com.

\section{REFERENCES}

[1] Choudhury M, Shanmuganathan N, Padmanabhan TV, et al. Rehabilitation of postsurgical maxillectomy defects using interim obturators-a case series. Indian J Surg Oncol 2014;5(4):315-20.

[2] Miglani DC, Drane JB. Maxillofacial prosthesis and its role as a healing art. J Pros Den 1959;9:159-68.

[3] Hou YZ, Huang Z, Ye HQ, et al. Inflatable hollow obturator prostheses for patients undergoing an extensive maxillectomy: a case report. Int J Oral Sci 2012;4(2):1148.

[4] Tautin FS, Schoemann D. Retaining a large facial prosthesis. J Prosthet Dent 1975;34(3):342-5.

[5] McClelland RC. Facial prosthesis following radical maxillofacial surgery. J Prosthet Dent 1977;38(3):327-30.

[6] Fattore L, Edmonds DC. A technique for the obturation of anterior maxillary defects with accompanying midfacial tissue loss. J Prosthet Dent 1987;58(2):203-5.
[7] Dumbrigue HB, Fyler A. Minimizing prosthesis movement in a midfacial defect: a clinical report. J Prosthet Dent 1997;78(4):341-5.

[8] Kiat-amnuay S, Khan Z, Goldsmith LJ, et al. Effect of adhesive retention on maxillofacial prostheses. Part I: skin dressings and solvent removers. J Prosthet Dent 2000;84(3):335-40.

[9] Wolfaardt JF, Tam V, Faulkner MG, et al. Mechanical behavior of three maxillofacial prosthetic adhesive systems: a pilot project. J Prosthet Dent 1992;68(6):9439.

[10] Parel SM. Diminishing dependence on adhesives for retention of facial prosthesis. J Prosthet Dent 1980;43(5):552-60.

[11] Chang TL, Garrett N, Roumanas E, et al. Treatment satisfaction with facial prosthesis. J Prosthet Dent 2005;94(3):275-80.

[12] Nishimura RD, Roumanas E, Moy PK, et al. Nasal defects and osseointegrated implants: UCLA Experience. J Prosthet Dent 1996;76(6):597-602.

[13] Pruthi G, Jain V, Sikka S. A novel method for retention of an orbital prosthesis in a case with continuous maxillary and orbital defect. J Indian Prosthodont Soc 2010;10(2):132-6. 